EPJ Web of Conferences 92,02072 (2015)

DOI: $10.1051 /$ epjconf/ 20159202072

(C) Owned by the authors, published by EDP Sciences, 2015

\title{
Calibration of Virtual Testing Stand of the Car Cabin using climatic chamber tests
}

\author{
Jan Pokorny ${ }^{1, a}$, Jan Fiser ${ }^{1}$ and Miroslav Jicha ${ }^{1}$ \\ ${ }^{1}$ Brno University of Technology, Faculty of Mechanical Engineering, Energy Institute, Technicka 2896/2, Brno, \\ Czech Republic
}

\begin{abstract}
The aim of our research is to calibrate and verify of the software Virtual Testing Stand of the Car Cabin using climatic chamber tests. The Virtual Testing Stand is standalone executable software developed in Matlab for prediction of the cabin environment and thermal heat load by using the time-efficient heat balance model. The main limitation of the simulation method is a simplified convection scheme inside a cabin using the empirical correlations instead of the CFD simulations. In this paper we present the first preliminary tests of the calibration process and verification of the simulation results. Tests were carried out for the car Skoda Octavia Combi with the silver metallic paint. The material composition of the test car was deeply explored and the material properties of the cabin were identified as accurate as possible. The car was exposed to the various environments inside a climate chamber. In this paper we report about two performed tests: summer solar soak test and winter heat-up test with the defined heat source.
\end{abstract}

\section{Introduction}

Climate chamber measurements are a common way to identify the thermal behaviour of the tested system repeatedly. A climate chamber can provide precisely defined environmental conditions for various climates. This is essential for car manufactures, which need to test and prove the functionality of specific car components during various operational and weather conditions (engine, HVAC, etc.).

Our research team [1] is focused on the issue of thermal comfort and thermal management of the vehicle cabins. In this paper we refer about the first preliminary tests performed in the automobile climate chamber at the NETME centre [2] in Brno. We used the Skoda Octavia Combi car with a silver metallic paint. The scope of the tests was to verify the recently developed multi-air zone model, which is part of the Virtual Testing Stand of the Car Cabin (VTSCC) software developed on our institute.

The main software features were already presented in [3]: "The mentioned model is designed for the fast prediction of the car cabin environment during various operating conditions. Such kind of computational tool is useful during early stage of the new car and its HVAC system design. Main inputs of the model are weather data, operating conditions of car, geometry and material composition. Main outputs of the model are air zone and surface temperatures, air zone relative humidity and also car cabin heat load". These fast processing models also

\footnotetext{
${ }^{a}$ Corresponding author: pokorny.j@fme.vutbr.cz
}

allow conducting sensitivity studies $[4,5]$ and they can be used in real-time hardware-in-the-loop applications [6].

The multi-air zone model requires an advection scheme of the car cabin. The recommended method to solve the air flow inside cabins is to use CFD simulations; however the calculation becomes time consuming. One of the ways to reduce a computational time of the multi-air zone model is to create a looking up table of the pre-calculated typical scenarios using results from CFD simulations [7]. Other ways to solve this problem are to develop more sophisticated advection scheme, e.g. to consider also the effect of a gravity [8], or else to create empirical advection scheme by the deep calibration process. We would like to find a valid way to describe the airflow between the air zones inside a car cabin using the calibration process for various types of operational conditions.

\section{Methods}

The climate chamber equipped with the solar simulator was used for the experimental tests. Therefore we were able to investigate sunny weather conditions and car cabin solar heat gains. Two experimental tests were carried out with the Skoda Octavia car:

- "winter" heat-up test

- "summer" solar soak test

Both test started by three-hour period of preconditioning then followed by the period of the own test lasting four ("winter" test) respectively three hours ("summer" test). 
During the "winter" test case the temperature in the climate chamber was setup to the $T_{\text {out }}=5{ }^{\circ} \mathrm{C}$ and furthermore we added into the cabin an additional heating system to test the dynamics of car cabin heating-up. We used the portable oil-filled convection radiator heater, which supplied the car cabin by the power $P_{\text {in }}=1250 \mathrm{~W}$.

During the "summer" test case the temperature in the climate chamber was setup to $T_{\text {out }}=30{ }^{\circ} \mathrm{C}$, and the intensity of the solar radiation to $q_{s r}=800 \mathrm{~W} / \mathrm{m}^{2}$.

In both cases the air temperatures inside the car cabin were measured with six wireless probes using the Testo 435 data logger. The locations of the probes were following: at the co-driver's place and the passenger's place on the rear seat (behind driver). For each placement, there were three probes located at the different vertical level: the feet, seat and head level. The locations of the probes were selected with respect to our aim to split a car cabin model into multiple air zones: Head, Seat and Feet zone. They are depicted in the figure 1, where a print-screen of the VTSCC application is shown.

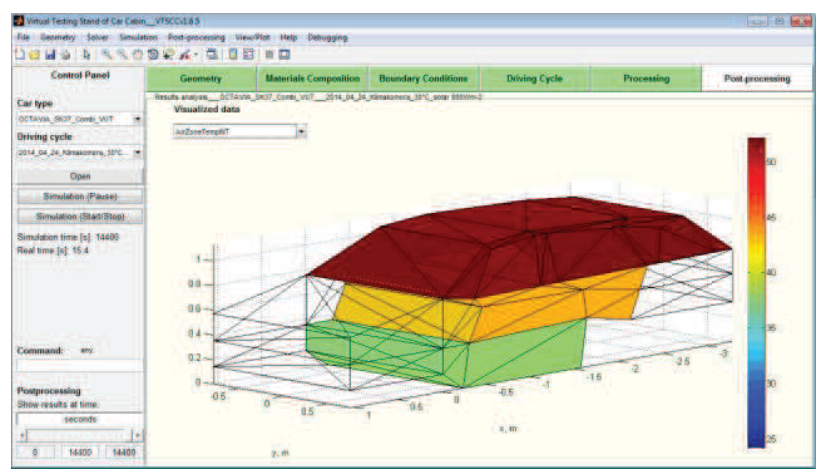

Figure 1. Post-processing panel with air zones temperatures (Head, Seat, Feet) at time 14400 s of solar soak test

The mean air temperature predicted by the model was compared with the measured mean air temperature inside a car cabin, which was calculated as an average of the all measured air temperatures, see figure 4 and 7 in the chapter 3 Results.

\section{Results}

\section{1 'Winter' heat-up test}

The winter season conditions were artificially created inside a climate chamber for the outside temperature $5{ }^{\circ} \mathrm{C}$. The effect of the heating during a winter season was simulated using a radiator heater placed on the rear seat. The heating power of the radiator was measured using the digital plug power meter, see figure 2 . The test procedure is defined by Table 1, where the most important events of the experimental investigation are written. These values were converted into the input file Timetable.csv of the VTSCC application see Table 2. Where time $v(\mathrm{~km} / \mathrm{h})$ is the velocity of the air flow around the car, $T_{\text {out }}\left({ }^{\circ} \mathrm{C}\right)$ and $R H_{\text {out }}(\%)$ are temperature and relative humidity inside a climate chamber, $q_{s r}\left(\mathrm{~W} / \mathrm{m}^{2}\right)$ intensity of solar radiation, $P_{\text {in }}$ (W) internal heat sources from passengers or additional heat sources, $T_{\text {vent }}\left({ }^{\circ} \mathrm{C}\right)$ and $R H_{\text {vent }}\left({ }^{\circ} \mathrm{C}\right)$ are temperature and relative humidity of ventilation airflow and $V_{\text {vent }}(\mathrm{l} / \mathrm{s})$ is its volumetric flow rate, $T_{\text {air,mean }}\left({ }^{\circ} \mathrm{C}\right)$ is averaged measured air temperature inside a car cabin, which was used for the model verification and the initial temperature definition for the all cabin's parts.

Table 1. "Winter" heat-up test diary

\begin{tabular}{|r|r|l|}
\hline \multicolumn{1}{|c|}{ sec } & \multicolumn{1}{c|}{ time } & \multicolumn{1}{|c|}{ Event } \\
\hline-10830 & $7: 32$ & Climate chamber start \\
\hline-4980 & $9: 09$ & One person got in the car \\
\hline-4140 & $9: 23$ & One person left the car \\
\hline-1500 & $10: 07$ & Closing the side windows \\
\hline 0 & $10: 32$ & $\begin{array}{l}\text { Radiator on: starting power } 1300 \mathrm{~W} \\
\text { Stabilized radiator power to } 1250 \mathrm{~W}\end{array}$ \\
\hline 14400 & $14: 37$ & End test \\
\hline
\end{tabular}

Table 2. "Winter" heat-up test input file

\begin{tabular}{|c|c|c|c|c|c|c|c|c|c|}
\hline 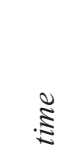 & 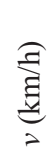 & 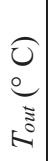 & $\underset{\frac{1}{2}}{\stackrel{2}{2}}$ & $\frac{\overparen{\text { TI }}}{\sum_{5}^{3}}$ & $\sum_{i}^{\equiv}$ & $\underbrace{0}_{\approx}$ & 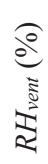 & 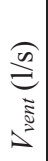 & 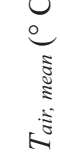 \\
\hline $10: 32$ & 10 & 5 & 50 & 0 & 1250 & 5 & 50 & 0 & 7.6 \\
\hline $14: 37$ & 10 & 5 & 50 & 0 & 1250 & 5 & 50 & 0 & 27.5 \\
\hline
\end{tabular}

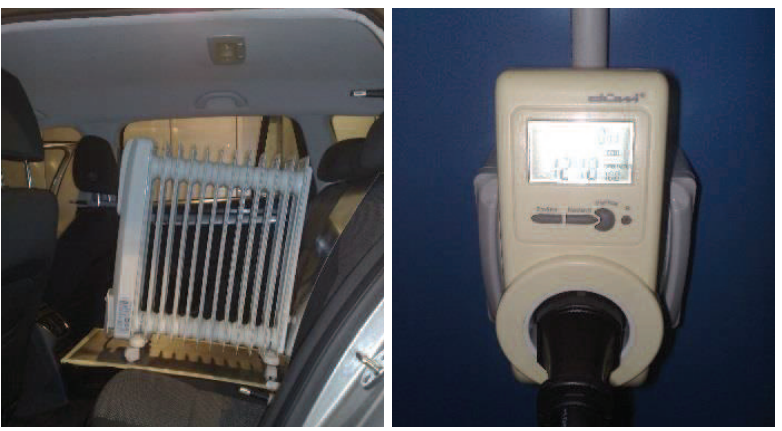

Figure 2. Heat-up test, the radiator heater (left) and plug power meter (right).

The graph on the figure 3 shows the results of the performed experimental test including a preconditioning period the test. Plotted temperatures were calculated for the each vertical level as an average of the temperature at co-driver and the rear seat. During the cooling of the car the highest temperature was at feet level and the lowest at the head level, because we left the side window opened. It was opened till $t=-1500$ (s) to speed up the cooling process of the cabin interior; except the time interval between $t=[-4980,-4140]$ (s) when one person did some adjustments inside the cabin. After three hours the air inside a car cabin was stabilized on to the $7.6{ }^{\circ} \mathrm{C}$, which was considered as the initial state for the simulation. When the car cabin temperature was stabilized the portable oil-filled convection radiator heater on the rear seat was switched on. The plug power meter measured the internal heat sources. At the start of the test $t=0(\mathrm{~s})$ it had shown the power $1300 \mathrm{~W}$, after a while the power was stabilized onto the $1250 \mathrm{~W}$. This heating power may seem to be low for the heating-up the car cabin during winter season. However, it should be noted that the wind speed around the car inside the 
climate chamber was very low up to $10 \mathrm{~km} / \mathrm{h}$ and there were no ventilation and demand to heat up the fresh air from the outside. At the end of the test the temperature difference between the front and the rear seat for the each vertical level were following: head $41.4-43{ }^{\circ} \mathrm{C}$, seat 22 $-27.1^{\circ} \mathrm{C}$, and feet $15.6-15.9^{\circ} \mathrm{C}$. It means that the most influenced probe by the radiator heater placement was the seat probe on the rear seat. On the contrary, there was almost no influence at the feet level.

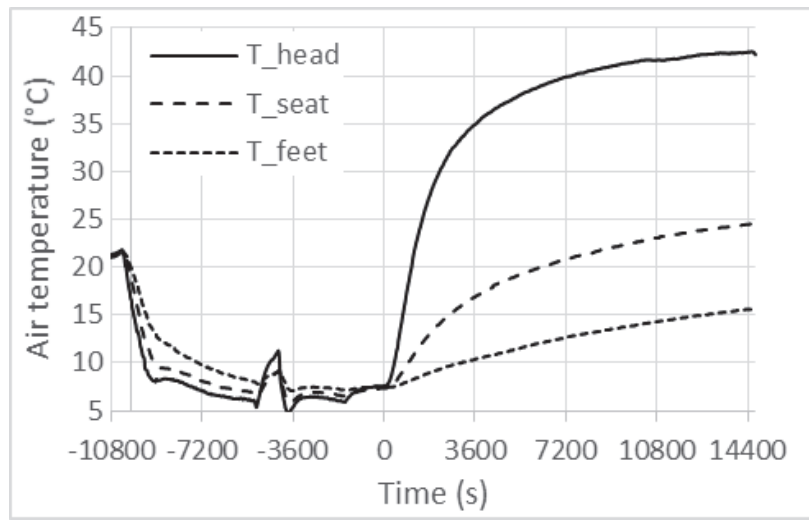

Figure 3. Radiator heat-up test - measured air temperatures

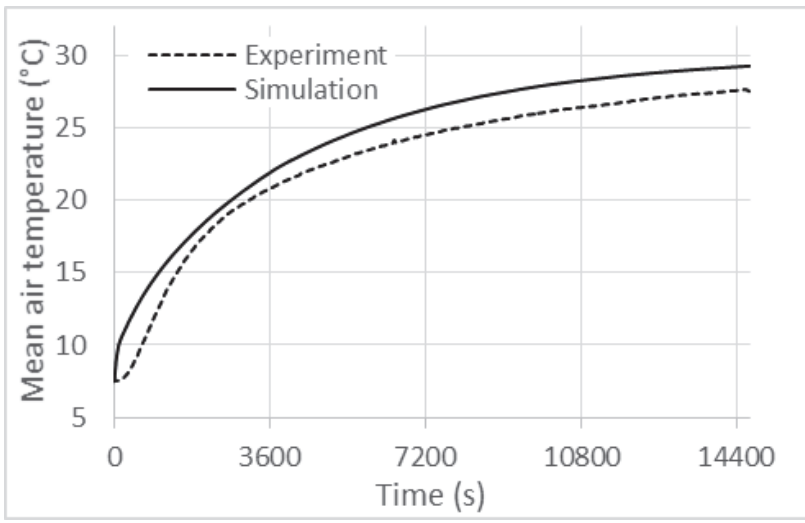

Figure 4. Radiator heat-up test - comparison of measured and predicted mean cabin air temperature

Our model is able to predict the overall state of the car cabin well. The model predicts the mean air temperature with maximal difference of the $2{ }^{\circ} \mathrm{C}$, see figure 4 . However the fit of the local air temperatures needs to be improved by implementing more advanced advection scheme; its development is underway.

\section{2 "Summer" solar soak test}

The summer season conditions were artificially created inside a climate chamber for the outside temperature $30{ }^{\circ} \mathrm{C}$ and the solar intensity $800 \mathrm{~W} / \mathrm{m}^{2}$, to simulate the parking summer test case. The test procedure is defined by Table 3 and the input file is specified in Table 4 .

During the preconditioning period the air temperature inside a cabin was influenced by some adjustments, which we did in the cabin. However these adjustments had no effect on the verification process.

After three hours the air inside a car cabin was stabilized on to the $28.9{ }^{\circ} \mathrm{C}$, which was considered as the initial state for the simulation. When the car cabin temperature was stabilized, the solar lamps were switched on and they gave off $800 \mathrm{~W} / \mathrm{m}^{2}$ from the perpendicular direction to the roof, see figure 5, left. On the right, there is shown a wireless Testo probe measuring the relative humidity $(\mathrm{RH})$ and the air temperature at the seat level of the co-driver's place. In the figure 6 the measured temperatures for each air zone are plotted. The temperature differences between the air zones (head seat) and (seat - feet) are very similar. The air temperatures mostly depend on the vertical distance between the probe placement and the floor of car cabin.

Table 3. "Summer" solar soak test diary

\begin{tabular}{|r|r|l|}
\hline \multicolumn{1}{|c|}{ sec } & time & \multicolumn{1}{|c|}{ Event } \\
\hline-10186 & $9: 02$ & Climate chamber start to set point $30^{\circ} \mathrm{C}$ \\
\hline 0 & $11: 52$ & Solar lamps on: intensity $800 \mathrm{~W} / \mathrm{m}^{2}$ \\
\hline 8414 & $14: 12$ & One person got in the car \\
\hline 8684 & $14: 16$ & One person left the car \\
\hline 11504 & $15: 03$ & End test \\
\hline
\end{tabular}

Table 4. "Summer" solar soak test input file

\begin{tabular}{|c|c|c|c|c|c|c|c|c|c|}
\hline ミ & 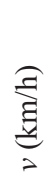 & $\underbrace{0}$ & 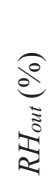 & 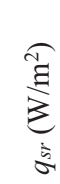 & 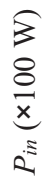 & 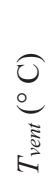 & 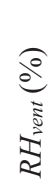 & 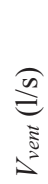 & 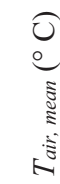 \\
\hline $11: 52$ & 10 & 30 & 45 & 800 & 0 & 30 & 45 & 0 & 28.9 \\
\hline $15: 03$ & 10 & 30 & 45 & 800 & 0 & 30 & 45 & 0 & 42.4 \\
\hline
\end{tabular}

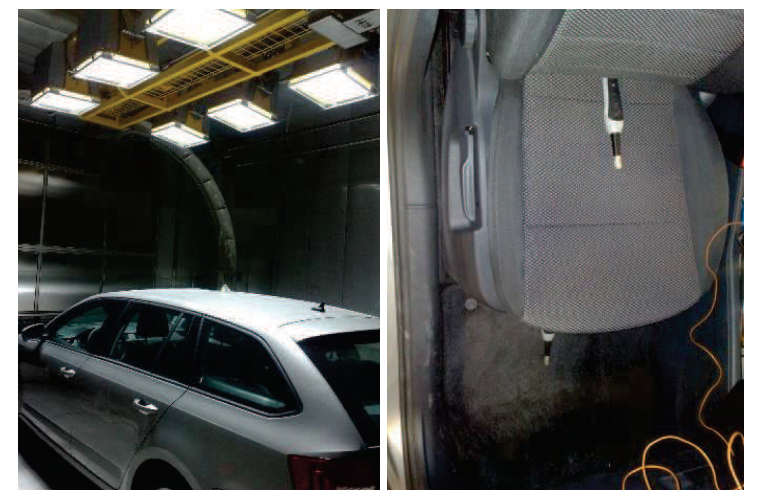

Figure 5. Solar soak test of the car in the climatic chamber (left). The RH, temp. probe Testo on the front seat (right).

At the end of the test the temperature difference between the front and the rear seat for the each vertical level were following: head $47.3-46.3{ }^{\circ} \mathrm{C}$, seat $43.6-$ $41.8{ }^{\circ} \mathrm{C}$, and feet $39.3-36.2{ }^{\circ} \mathrm{C}$. It means that temperature inside a car cabin was slightly higher at the co-driver's seat. It can be explained by the proximity of windshield which transmitted the most of the solar heat load into the cabin. In this case the air profile in vertical axes due to the air stratification was more linear. The model predicts the air mean temperature less accurate then in the first scenario with the maximal difference of the $4{ }^{\circ} \mathrm{C}$, during the transient, see figure 7 . The transient behaviour of the model is more sensitive to the outside conditions than the thermal behaviour of the real car cabin, however the stabilized temperature at the end of the test is quite close to the predicted mean air temperature; the difference is less than $2^{\circ} \mathrm{C}$. 


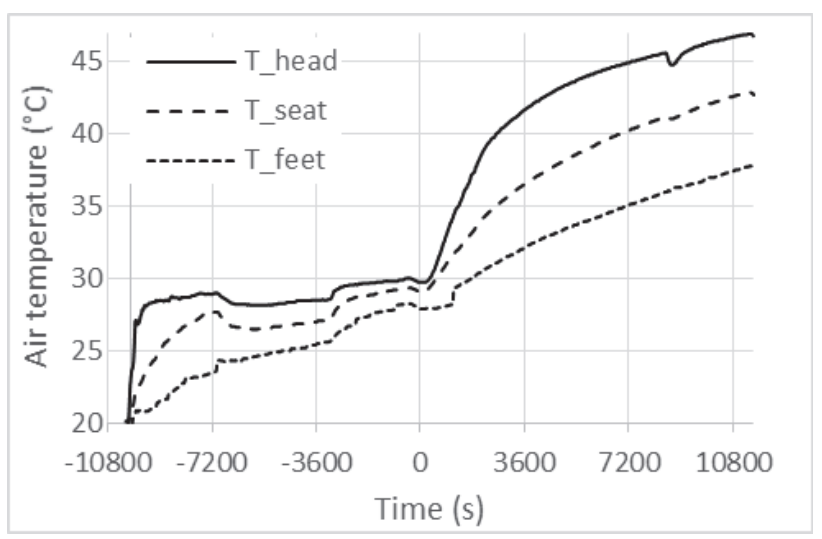

Figure 6. Solar soak test - measured air temperatures

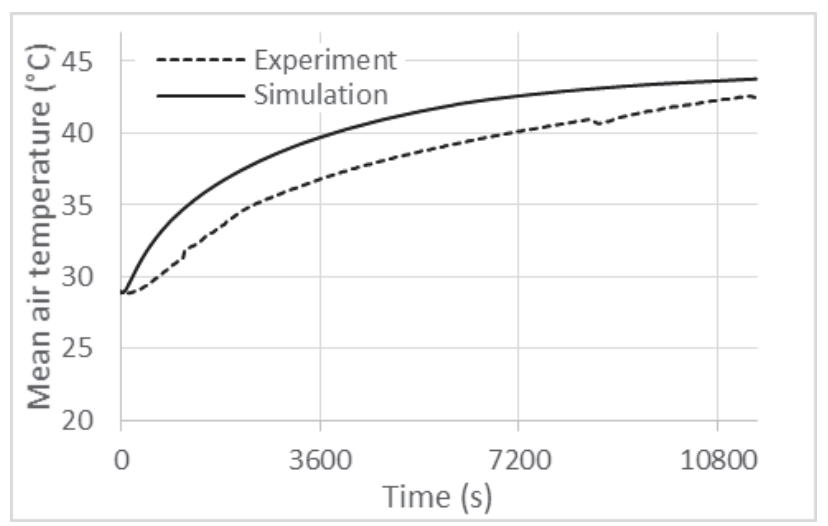

Figure 7. Solar soak test - comparison of measured and predicted mean cabin air temperature

\section{Discussion}

From this two test cases (figures 3 and 6) can be seen that the heat gains from the radiator and the solar simulator has a different impact on the air stratification inside the car cabin. When the solar heat load (i.e. external heat source) was considered the temperature difference between the air zone levels were almost constant. However in the case of the radiator (i.e. internal heat source) the situation was different. The air stratification was more significant and at the head level was substantially higher temperature than in the other zones.

The main limitation of the current model is a missing detailed advection scheme; at the moment the heat flows between the air zones set by the matrix $Q_{A}$ of fitting advection coefficients describing the power (time derivative of moist air enthalpy). In the presented tests was assumed $Q_{A}=[200-158.1-41.9]$. It means that due to the gravitation field the $200 \mathrm{~W}$ was flowing into Head zone; 158.1 W from the Seat zone and 41.9 W from Feet zone. Without this assumption about convection between air zones the prediction of the mean air temperature and mainly of the local air temperatures will be less accurate. It is due to the fact that only naturally driven air flow was present in these tests, thus the effect of the gravity force on the air stratification cannot be neglected.

\section{Conclusion}

At the moment the model is suitable for the calculation of the mean air temperature (figures 4 and 7) and overall heat balance of the car cabin. The dynamical model predicted the the cabin mean air temperatures for these test cases with the accuracy of $2{ }^{\circ} \mathrm{C}$, when the car cabin is close to the steady state. The higher differences (maximally $4{ }^{\circ} \mathrm{C}$ ) occurred during a transient state of the solar soak test. The inaccuracy of the predictions is acceptable for such kind of the model with the processing time in order of seconds.

The plan for the future work is to perform more experimental tests of various operational conditions to establish and validate an empirical advection model instead of considering constant advection coefficients. We expect that a more sophisticated advection model will improve the accuracy of prediction of air temperature in all three air zones in the model.

\section{References}

1. Brno University of Technology. Laboratory of thermal comfort. Available from

http://www.energetickeforum.cz/faculty-ofmechanical-engineering-of-brno-universityof/laboratore/laborator-tepelneho-komfortu accessed on 24-09-2014

2. NETME Centre, Division of Power, Process and Environmental Engineering. Available from http://www.netme.cz/en/ accessed on 24-09-2014

3. J. Pokorny, J. Fiser, M. Jicha, Advances in engineering software 76 (2014)

4. J. Pokorny, J. Fiser, M. Jicha, EPJ Web of Conferences 67, 02096 (2014)

5. R. Levinson, Pan H., G. Ban-Weiss, P. Rosado et al., Applied Energy 88, 12 (2011)

6. D. Michalek, C. Gehsat, R. Trapp, T. Bertram, Hardware-in-the-loop-simulation of a vehicle climate controller with a combined HVAC and passenger compartment model, Proceedings of 5th International Conference On Advanced Intelligent Mechatronics, Monterey, USA, 1065-1070 (2005)

7. D. Müller, R. Streblow, B. Flieger, A. Jachens, Automobiltechnische Zeitschrift (ATZ) worldwide eMagazines, 113, 11 (2011)

8. V. Norrefeldt, G. Grün, C. van Treeck, Use of the VEPZO model to optimize a hybrid ventilation system. Proceedings of $4^{\text {th }} I B P S A-G e r m a n y$ Conference BauSIM, 2012, Berlin, 369-377 (2012).

\section{Acknowledgement}

The authors gratefully acknowledge the support from the following projects. The project CZ.1.07/2.3.00/30.0005 and the project Reg. No. FSI-S-14-2355 of the Brno University of Technology; the "Josef Bozek Competence Centre for Automotive Industry" TE01020020 of the Technology agency of the Czech Rep.; the NETME Centre (New Technologies for Mechanical Engineering), Reg. No. CZ.1.05/2.1.00/01.0002 and, in the follow-up sustainability stage, supported through NETME CENTRE PLUS (LO1202) by financial means from the Ministry of Education, Youth and Sports of the Czech Rep. under the „National Sustainability Programme I”. 